\title{
Osteopetrosis: Case Report
}

\section{Edir Soccol Junior ${ }^{1 *}$, Mauro Grinfelder ${ }^{2}$, Caroline Rafaela Solano ${ }^{3}$, Maria Eduarda Oro Dilly ${ }^{3}$, Willian Gustavo Tasca ${ }^{3}$, Rubia M Alves ${ }^{3}$, Lilian C Meneguzzo ${ }^{3}$, Neri Machado Junior ${ }^{1}$, Fabio Cavali ${ }^{1}$, Fernando Soccol $^{1}$, Haiana Cavalheiro ${ }^{1}$ and Ronan Bertinatto ${ }^{1}$}

${ }^{1}$ Department of Orthopedics and Traumatology of the Pato Branco Polyclinical Institute, Paraná, Brazil

${ }^{2}$ Orthopedics and Traumatology Resident, Department of Orthopedics and

Traumatology of the Pato Branco Polyclinical Institute, Paraná, Brazil

${ }^{3}$ Medicine Student from the University Center of Pato Branco, Pato Branco, Paraná,

Brazil

*Corresponding Author: Edir Soccol Junior, Department of Orthopedics and Traumatology, Department of Hip and Pelvic Surgery of the Pato Branco Polyclinical Institute, Paraná, Brazil.
Received: March 18, 2021

Published: April 15, 2021

(C) All rights are reserved by Edir Soccol Junior., et al.

\section{Abstract}

Introduction: Case report of osteopetrosis with bilateral diaphyseal femoral fracture, with therapeutic approach.

Objective: To present a report about a 33-year-old youngster, carrying osteopetrosis, who was admitted in emergency service with bilateral diaphyseal femoral fracture, and the adopted therapy.

Methodology: The information present in this paper was taken from the anamnesis and the physical exams of the patient, medical and photographic records review of the diagnostic methods and the therapy adopted in the treatment; it has been performed a literature review.

Conclusion: The report seeks to call the colleagues attention to a rare and difficult to handle disease which needs surgical treatment of high technical difficulty, whose planning must be discerning, especially in the fixing mechanism choice. Besides that, the rehabilitation must be gradual and circumspect, considering the high number of pseudoarthrosis cases.

Keywords: Osteopetrosis; Pseudoarthrosis; Bilateral Diaphyseal Femoral Fracture

\section{Introduction}

Osteopetrosis, also known as Albers-Schonberg Disease (German radiologist responsible for the first description of the illness, in 1904) or marble bone disease, is a rare genetical condition characterized by a bone resorption flaw and skeletal anomalies [1,2]. It is a disease with ample symptoms, heterogenous gravity and which happens hereditarily. Its diagnosis is made based on clinical and, mainly, radiological findings, seeking to observe distortions in bone modelling, focal and multiple sclerosis. In addition, according to Tolar., et al. (2004), usually, its appearance in the image exams is of "a bone inside a bone" and "sandwich vertebrae" due to the increased bone density characteristic of the disease $[3,4]$. 
From the perspective of Stewar., et al. (2003), it is a disease of devastating neurometabolic character and it can be generated due to flaws in the proton bomb or in the chloride channel CIC-7. These bombs are responsible for the acidification of the bone surface below the osteoclast. The osteopetrosis etiology is also strongly related to failure of the osteoclasts differentiation or function and mutation in at least 10 genes which have already been identified in people carrying the disease $[5,6]$.

Its pathogenesis is still in constant study and it is better comprehended with reference to the development and function of the osteoclasts. This pathology can be divided in 3 clinical forms: 1 ) infantile or malignant autosomal recessive form, which contemplates manifestations in the first year of life and has an obscure prognosis, with a high rate of mortality; 2) autosomal recessive, intermediate form, with recurrent fractures and mandibular osteomyelitis; 3) adult or dominant autosomal form, benign, with a better prognosis and a great part of the patients asymptomatic [7].

Osteopetrosis affects all ages, but its prevalence is in white men. The autosomal recessive form (ARO) has an incidence of 1 in 250,000 births, the infantile being called a classical occurrence. It manifests itself in the first years of life and generates severe disfunctions, such as: hematopoiesis, obliteration of the cranial nerves foramen, microcephaly, growth and neuropsychomotor development retardation. According to Brunch., et al. (2009), the bones have greater accumulation of calcium salts, therefore they are hard, but they do not adapt well to stress, becoming brittle. Generally, death occurs in the first years of life, due to severe bleeding or anemias $[8,12]$.

The adult or dominant autosomal form occurs in around 5 : 100.000 births, being the most common one. The main complications are confined to the skeleton, including fractures, scoliosis, hip osteoarthritis and osteomyelitis, affecting particularly the mandible in association with tooth abscess or caries [9]. The most found presentations, in $75 \%$ of the cases, are frequent fractures, affection mostly long bones, with emphasis on the proximal third of the femur and the proximal third of the tibia. Usually, these fractures are associated with significant intra and postoperative complications.

Among the possible consequences of this pathology, the most severe occurs in the nervous system. Cranial nerves, blood vessels and the spinal cord are compressed by gradual occlusions or by the cranial foramen lack of growth [10]. Most patients have some optic atrophy degree and in more severe cases it can lead to blindness. The facial and trigeminal nerves can also be affected, developing hydrocephalus. It can also occur stenosis of the arterial (internal and vertebral carotid arteries) and venous supply [9].

According to Chawla and Kwek [10], the variable answer for the bone healing always represents a significant challenge for the orthopedic surgeon. It is necessary to be extremely careful when handling with the fractures of patients with osteopetrosis. Furthermore, because it is an unusual disease, there are scarce publications about clinical and surgical management of these fractures in pathological bone. Along with that, there is a high incidence of breaking instruments during the surgical process due to the bone hardness, besides the difficulty to perform the fixation. Thus, the advantages and disadvantages must be cautiously analyzed for the surgical treatment lineation $[10,11]$.

\section{Objective of the Study}

To present a report about a 33-year-old youngster, carrying osteopetrosis, who was admitted in emergency service with bilateral diaphyseal femoral fracture and the adopted therapy.

\section{Methodology}

The information present in this paper was taken from the anamnesis and the physical exams of the patient, medical and photographic records review of the diagnostic methods and the therapy adopted in the treatment; it has been performed a literature review.

\section{Case Report}

33-year-old patient admitted in emergency service due to falling on the same level after losing balance. The patient complained of thigh bilateral pain, compromising the ability to flex and mobilize lower members.

The physical exam presented deformity in both thighs, as well as reduced range of movement. Normal perfusion and neurological exams. It also presented stigmas of the underlying disease, such as visual and hearing modifications, craniofacial deformities and short height.

It was required simple thigh and pelvis x-rays, which showed femoral bone deformities in Erlenmeyer flask, besides an increased global bone opacity. Bilaterally, it presented cross-sectional shaft fractures (AO 32 A 3) (Picture 1). 

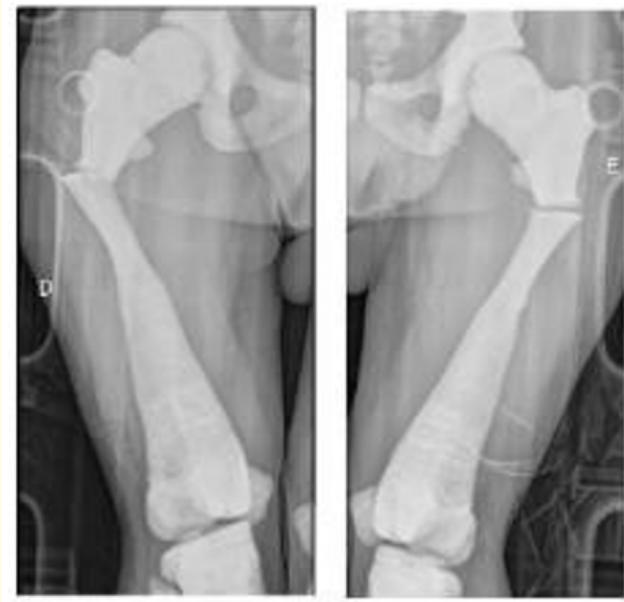

Picture 1: Simple x-rays presenting deformities.

It was indicated surgical treatment, preoperative period appropriated to the comorbidities of the patient and bilateral skin traction for one day until the arrival of suitable drills for this pathology. Thus, the chosen treatment was fixation with plate and screws.

\section{Results}

Picture 2 shows the immediate postoperative with adequate reduction and fixation of the fractures. Picture 3 shows the consolidation after years. After the rehabilitation period, around 6 months, the patient returned to walk again without support.

\section{Discussion}

Considering it is a disease of high impact in the quality of life of the patient and it is associated to multiple complications, if not diagnosed and/or treated appropriately in advance, osteopetrosis must always be remembered in osteochondropathies differential diagnoses. The fractures are highly associated [13-15] and several fixation methods have been studied $[13,16]$, due to the high rates of consolidation failure $[13,15]$.

In the present case, it has been opted for osteosynthesis by open reduction and internal fixation with plate and screws, remembering the possibility of technical difficulties due to the cortical thickness and small spinal canal, with the suggestion, in several articles, of the necessity of low speed and high torque drills, local hydration with saline solution and constant cleaning of the drills [18].
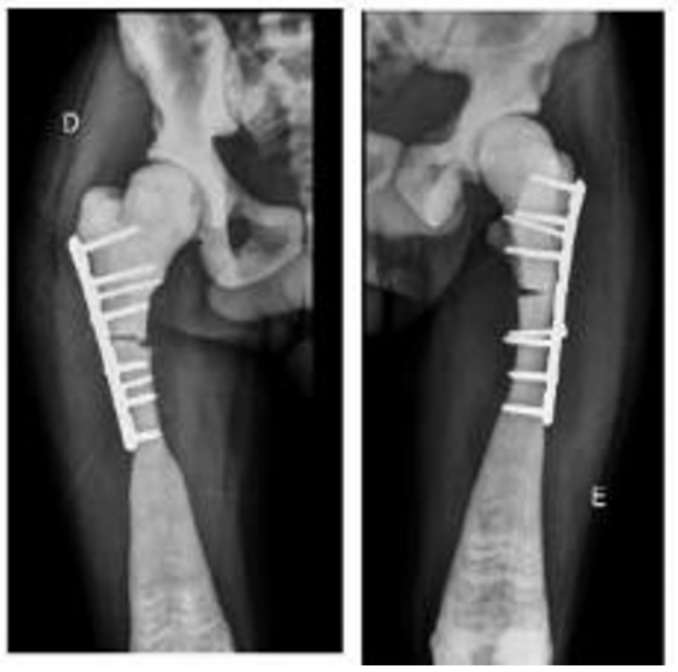

Picture 2: Simple x-ray of the immediate postoperative.

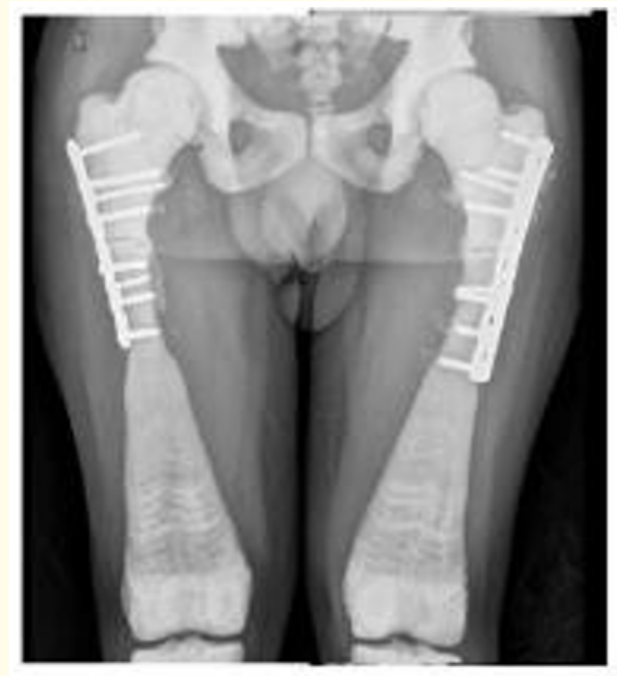

Picture 3: Simple x-ray after 6 months of postoperative rehabilitation.

\section{Conclusion}

The report seeks to call the colleagues attention to a rare and difficult to handle disease which needs surgical treatment of high 
technical difficulty, whose planning must be discerning, especially in the fixing mechanism choice. Besides that, the rehabilitation must be gradual and circumspect, considering the high number of pseudoarthrosis cases.

\section{Bibliography}

1. Bruch TatianaP., et al. "Osteopetrose. (Osteopetrosis)". Acta Reumatology Port's 34 (2009): 134-135.

2. Barba Mario Flores., et al. "Osteopetrose: relato dedoiscasose diagnostic por imagem. (Osteopetrosis: report of two cases and image diagnosis)". Pediatria (1995): 60-63.

3. Stark Zornitza and Savarirayan Ravi. "Osteopetrosis". Orphanet Journal of Rarediseases 4.1 (2009): 5.

4. Key Lyndonetal. "Treatment of congenital osteopetrosis with high-dose calcitriol". New England Journal of Medicine 310.7 (1984): 409-415.

5. Tolar Jakub., et al. "Osteopetrosis". New England Journal of Medicine 351.27 (2004): 2839-2849.

6. Delfattore Andrea., et al. "Genetics, pathogenesis and complications of osteopetrosis". Bone 42.1 (2008): 19-29.

7. Khawali Cristina., et al. "Retardo de desenvolvimento associado a osteopetrose. (Development retardation associated to osteopetrosis)". Arquivos Brasileirosde Endocrinologia and Metabologia 42.6 (1998): 483-488.

8. Borsato Maria L., et al. "Osteopetrose maligna: transplante de medula óssea. (Malignant osteopetrosis: bone marrow transplant)". Revista Brasileirade Hematologia e Hemoterapia 30.2 (2008): 168-171.

9. Chakrabarti Anirikh., et al. "A review of the mammalian unfolded protein response". Biotechnology and Bioengineering 108.12 (2011): 2777-2793.

10. ChawlA Anuj., et al. "Fraturas em pacientes com osteopetrose, insights deumaúnica instituição. (Fractures in patients with osteopetrosis, insights of a single institution)". Ortopedia Internacional 43.6 (2019): 1297-1302.

11. Heczey Andras and Louis Chrystal. "Osteopetrosis and Erlenmeyer-Flask Deformity". The New England Journal of Medicine 373.10 (2015): e12.

12. Bryk Junior Agostinho., et al. "Amaurose bilateral por osteopetrose congênita: relato decaso e revisão da literatura. (Bilateral amaurosis due to congenital osteopetrosis: case report and literature review)". Arquivos Brasileiros de Oftalmologia 64.3 (2001): 251-253.

13. Sonohata Motoki., et al. "Bipolar hip arthroplasty for subtrochanteric femoral nonunion in an adult with autosomal dominant osteopetrosis type II". Journal of Orthopaedic Science 16.5 (2011): 652-655.

14. Birmingham Patrick and Mchale Kathleen A. "Treatment of subtrochanteric and ipsilateral femoral neck fractures in an adult with osteopetrosis". Clinical Orthopaedics and Related Research 466.8 (2008): 2002-2008.

15. Bhargava Amit., et al. "Challenges in the management of fractures in osteopetrosis"! Review of literature and technical tips learned from long term management of seven patients". Injury 40.11 (2009): 167-1171.

16. Kulkarni Jyoti V., et al. "Osteopetrosis-a challenge in rare situation. Case report". Journal of Evolution of Medical and Dental Sciences 1.4 (2012): 532-537.

17. Rafiq Imranetal. "A new modality of treatment for non-united fracture of the humerus in a patient with osteopetrosis: a case report". Journal of Medical Case Reports 3.1 (2009): 15.

18. Kumbaraci Mert., et al. "Treatment of bilateral simultaneous subtrochanteric femur fractures with proximal femoral nail antirotation (PFNA) in a patient with osteopetrosis: case report and review of the literature". Journal of Orthopaedic Science 18.3 (2013): 486-489.

\section{Assets from publication with us}

- Prompt Acknowledgement after receiving the article

- Thorough Double blinded peer review

- Rapid Publication

- Issue of Publication Certificate

- High visibility of your Published work

Website: www.actascientific.com/

Submit Article: www.actascientific.com/submission.php

Email us: editor@actascientific.com

Contact us: +919182824667 